\title{
THE INFLUENCE OF AN EARLY INTERVIEW ON LONG-TERM RECALL: A COMPARATIVE ANALYSIS
}

(INITRE IIOR NI:WI:OUNI)ISAND STUIDIISS

TOTAL OF IO PAGES ONLY MAY BE XEROXED 


National Library

of Canada

Acquisitions and

Bibliographic Services

395 Wellington Street Ottawa ON K1A ON4

Canada
Bibliothèque nationale

du Canada

Acquisisitons et services bibliographiques

395 , rue Wellington Ottawa ON K1A 0N4

Canada
Your file Votre référence ISBN: 0-612-89678-1

Our file Notre référence ISBN: 0-612-89678-1
The author has granted a nonexclusive licence allowing the National Library of Canada to reproduce, loan, distribute or sell copies of this thesis in microform, paper or electronic formats.

The author retains ownership of the copyright in this thesis. Neither the thesis nor substantial extracts from it may be printed or otherwise reproduced without the author's permission.
L'auteur a accordé une licence non exclusive permettant à la Bibliothèque nationale du Canada de reproduire, prêter, distribuer ou vendre des copies de cette thèse sous la forme de microfiche/film, de reproduction sur papier ou sur format électronique.

L'auteur conserve la propriété du droit d'auteur qui protège cette thèse. $\mathrm{Ni}$ la thèse ni des extraits substantiels de celle-ci ne doivent être imprimés ou aturement reproduits sans son autorisation.
In compliance with the Canadian

Privacy Act some supporting forms may have been removed from this dissertation.

While these forms may be included in the document page count, their removal does not represent any loss of content from the dissertation.
Conformément à la loi canadienne sur la protection de la vie privée, quelques formulaires secondaires ont été enlevés de ce manuscrit.

Bien que ces formulaires aient inclus dans la pagination, il n'y aura aucun contenu manquant. 

Running Head: Influence of an Early Interview

The Influence of an Early Interview on Long-Term Recall: A Comparative Analysis

Tracy Tizzard-Drover

A thesis submitted to the

School of Graduate Studies in

partial fulfillment of the

requirements for the degree

Master of Science.

Department of Psychology

Memorial University of Newfoundland and Labrador

January 2003

St. John's

Newfoundland 


\section{Table of Contents}

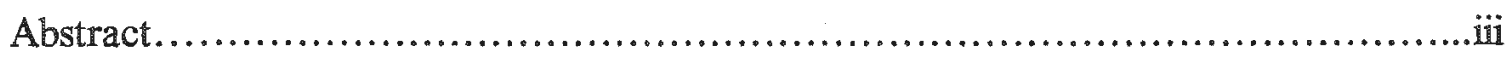

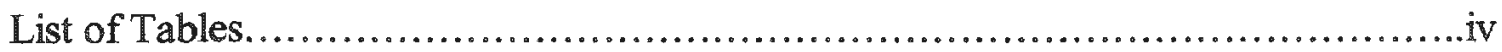

Figure Captions..................................................................

Acknowledgements.................................................................

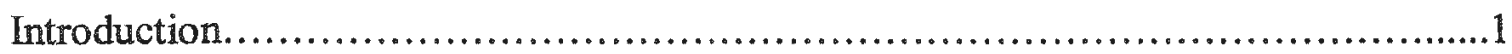

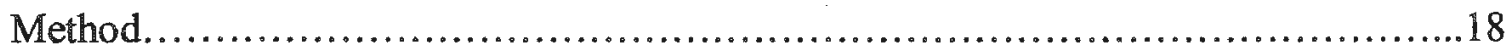

Participants................................................................ 18

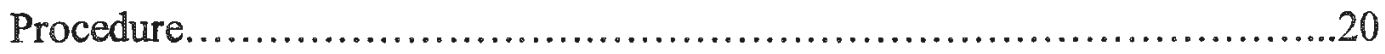

Scoring of Recall Data...................................................23

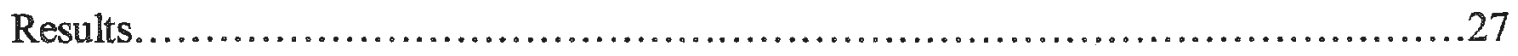

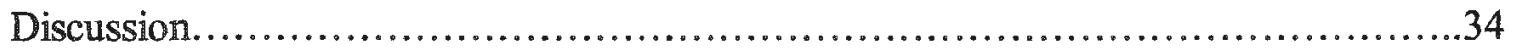

References........................................................................ 48

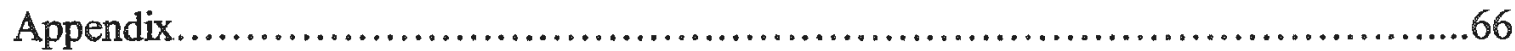


Influence of an Early Interview iii

\begin{abstract}
There is burgeoning participation by children in police investigations and in courtrooms as witnesses; therefore, there is significant concern about children's skill in recalling complete and accurate details. The author of the present study investigated one portion of this dynamic puzzle. The influence of early interviews on children's long-term recall of a traumatic event was evaluated by comparing the recall of three groups of 3- to 9-year-olds one year after their injury. One group had only one interview, a year after the injury; the second group had two interviews, one immediately after injury and the second one year after injury; and the third group had three interviews, immediately, 6 months and one year after injury. The percentage of information the children recalled after one year was assessed in regard to completeness of correct recall (percentage correctly recalled of what was actually relevant to the child) and accuracy (percentage correctly recalled from the total information recalled). It was found that recall memory was a function of age, the type of event being recalled, and the timing of the initial interview. The primary finding was that all children, regardless of age, showed extensive recall of the target event. However, having an interview immediately after the injury was associated with greater completeness of recall and accuracy for the 3- and 4-year-olds but did not make a difference for the older 5- to 9-year-olds. These results are suggestive of a social influence, namely that the highly structured and organized interview may have a beneficial effect on memory for some ages. Implications for questioning and testimony are discussed.
\end{abstract}




\section{List of Tables}

Table 1. Age Group Sample Size, Mean Age and Age Range for each Interview

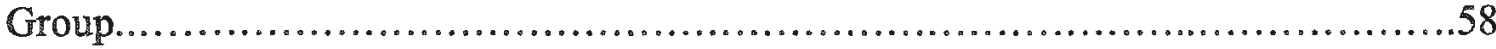

Table 2. Mean Percentages of Completeness of Memory Scores by Age and Number of

Interviews for Total Recall............................................................59

Table 3. Mean Percentages of Accuracy Scores by Age and Number of Interviews for

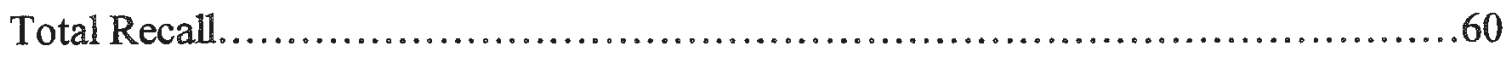

Table 4. Number of Children Not Providing Information in Free Recall..................61

Table 5. Mean Percentages of Completeness of Memory Scores by Age and Number of

Interviews for Free Recall. ........................................................... 62

Table 6. Mean Percentages of Accuracy Scores by Age and Number of Interviews for

Free Recall.....................................................................63 
Influence of an Early Interview v

\section{Figure Captions}

Figure 1. Age X Interview interaction for total recall completeness of memory scores comparing all three age groups..................................................64

Figure 2. Age $\mathrm{X}$ Interview interaction for total recall completeness of memory scores

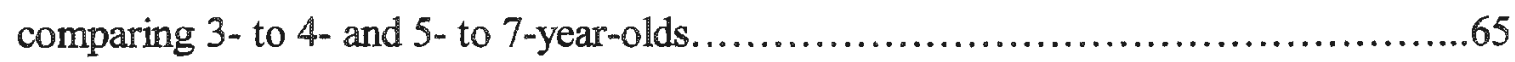




\section{Acknowledgements}

I would like to thank Dr. Carole Peterson for her supervision, statistical advice, expert editorial advice, and above all, her patience. The opportunity to work with children on extremely interesting, challenging and innovative research has been a wonderful academic experience. Many thanks to Penny Voutier for her guidance through scoring and patience with my countless questions. To my husband and children for their unconditional support and endless patience when mommy was "...at her 'big' school doing work on the computer." Finally, thank you to all the children, parents and other participants whose willingness and cooperation allowed the results of this study to be expressed - we are truly grateful. 
Influence of an Early Interview 1

The Influence of an Early Interview on Long-Term Recall: A Comparative Analysis

In recent years there has been a great deal of emphasis on children's long-term memory. This topic is forensically relevant since children's participation in the judicial system is significantly increasing and it is important to understand the level of accuracy of their recollections over the long-term as it bears directly on whether or not they will be considered credible witnesses. The legal profession appears to be of the opinion that with the passage of time children's memories become especially vulnerable and that the younger the child the more deleterious the effect (Flin, Boon, Knox, \& Bull, 1992). Consideration of accuracy, of course, is imperative for testimony in court; however the delay between event occurrence and testimony can affect children's memory. Many studies provide evidence that document children's accurate recall of traumatic events over the short-term (Peterson \& Bell, 1996; Rudy \& Goodman, 1991); however, it is queried whether this accuracy can be sustained over time. Because delays in the judicial system are typical, researchers have directed their attention to young children's long-term recollections of personally experienced, stressful events (Burgwyn-Bailes, Baker-Ward, Gordon \& Ornstein, 2001; Peterson \& Whalen, 2001; Quas et al., 1999).

Considerable research has investigated children's long-term memory and most studies have shown encouraging results with respect to children's accuracy (Peterson, 1999; Poole \& White, 1993; Quas et al., 1999). More specifically, children's memory is quite accurate even when assessed a year following the traumatic event (Burgwyn-Bailes 
et al., 2001; Peterson, Moores \& White, 2001). Moreover, Peterson and Whalen (2001) reported accurate recall in young children after 5 years had passed.

Although there have been encouraging results with respect to children's accurate recollection of traumatic events, the methodology employed by the above studies needs further examination. All studies had at least one interview prior to the delayed interview with most occurring shortly after the target event. The initial interviews isolated and addressed the traumatic event within several days or weeks of the target event. Subsequent interviews followed anywhere from 6 months (Peterson \& Bell, 1996), 1 or 2 years (Pipe, Gee, Wilson \& Egerton, 1999) to 5 years (Peterson \& Whalen, 2001; Quas et al.1999). It can be conceived that by interviewing children shortly after the target event using a highly structured format, the interviewers provide a well-organized template which may systematically enhance children's memory. Yet in the absence of initial questioning directly following the event, which is usual in abuse cases, recalled memories may become suspect. Altogether, caution is warranted in the interpretation of studies that include early interviewing for two reasons. Firstly, it is unknown what role the interview may have played in the initial consolidation of these apparent long-term memories; and secondly, it is unclear whether a structured interview shortly following the event might serve to genuinely 'inoculate' children from forgetting. Information with respect to these issues will have significant implications within the forensic domain, not to mention augment interpretation of previous findings. 
Although much research indicates that children are able to give worthwhile and accurate accounts if interviewed properly (Ceci \& Bruck, 1993; Fivush \& Schwarzmueller, 1995; Peterson \& Biggs, 1997; Peterson \& Grant, 2001), the primary concern here is whether their overall recall and accuracy of details can be maintained over long delays. There are studies that have investigated and assessed children's longterm recall - specifically delays of 5 to 11 years (Gold \& Neisser, 1980; Hudson \& Fivush, 1991; Peterson \& Whalen, 2001; Pillemer, Picariello \& Pruett, 1994; Quas et al., 1999). Hudson and Fivush (1991), for example, asked children to recall a kindergarten field trip to a museum six years later and subsequently found limited recall unless photographs (taken at the time) were used as prompts. What they did recall, however, was accurate. Similarly, in the Pillemer et al. (1994) study, children were queried about the details surrounding a fire alarm and school evacuation. Although the incident had taken place in their preschool 7 years previously, the recall for the children over 4 years of age was better than the recall for those under 4 years of age yet still far from complete. Moreover, the authors suggested that children 4 years of age and over had a more refined understanding of the temporal and causal sequence of events during an initial assessment and this was probably the reason they later exhibited more advanced long-term performance.

Even though the amount recalled in these studies was usually quite sparse, albeit reasonably accurate (Hudson \& Fivush, 1991; Pillemer et al, 1994), they do indicate that young children could recall details of personal events many years later. However, they 
address the issue of long-term memory with events that are benign and not personally relevant to the child. That is, while the child personally experienced these events, the events may not necessarily be sufficiently salient or personally relevant to the child to influence how much and what is remembered. A study by Rudy and Goodman (1991) shows that personally relevant, real-life experience is sufficient to heighten recollection regardless of whether events occurred to oneself personally or whether one only observed them happening to someone else. It is therefore plausible that if the target events to be remembered were experienced and were personally striking, then younger children's memories about that event would be better retained over long delays. Even though Rudy and Goodman's (1991) results were only measured in the very short-term (10-12 days), they still have implications for memory of witnesses, as well as victims of stressful experiences.

Quas et al. (1999) suggested that the nature of the events being recalled may play a key role in long-term recall, such that emotional events may be retained in memory much better and for longer periods of time than non-emotional events. Indeed, there is a long history of research with adults showing that emotional events are recalled over long delays with far better accuracy (Christianson, 1992; Rapaport, 1942) than less salient events. In contrast, laboratory research routinely reveals strong decrements in memory as a function of time delay for recall of items that are not personally salient. What is more, several researchers have been able to investigate children's long-term memory of extremely traumatic real-life events, such as abductions, rape, murder, and natural 
Influence of an Early Interview 5

disasters, and have found considerable recall in children of all ages (see review in Howe, 1997). These experiences were highly salient to the child and elevated levels of stress, fear and personal threat did not seem to impair their recall of the events; they remembered considerable detail about their experiences. While these studies allow the investigation of data not normally achieved through conventional and ethical methods and although the recollection of the children was significant, it is important to note that the experiences of the children varied widely and more importantly so did the focus of the researchers. The priority of the investigators was the psychological impact of these incidents and not necessarily the accuracy of reports and as a result many children were not systematically questioned. Furthermore, the methods of questioning, the delay between the events and the interviews, and the analyses of the children's reports varied extensively. These results did however challenge the notion of repression of traumatic events.

Although some research documents the facilitory impact of stressful events on memory, ethical investigation under controlled conditions using systematic procedures is extremely restricted. In an effort to study young children's memory of stressful events under ethically appropriate conditions, and with improved methodological rigor, researchers have investigated children's reports for a variety of personal medical experiences: medical/dental procedures (Baker-Ward, Gordon, Ornstein, Larus \& Clubb, 1993; Saywitz, Goodman, Nicholas \& Moan, 1991), inoculations and venipuncture (Goodman, Hirshman, Hepps, \& Rudy, 1991) voiding cystourethrograms (VCUGs) 
Influence of an Early Interview 6

(Goodman, Quas, Batterman-Faunce, Ridddlesberger \& Kuhn, 1994; Merritt, Ornstein \& Spicker, 1994), minor plastic surgery following accidents resulting in facial lacerations (Baker-Ward, Burgwyn, Ornstein \& Gordon, 1995) and dental exams some of which were painful or stressful to the child (Vandermaas, Hess \& Baker-Ward, 1993). All the studies found extensive recall; nevertheless, there were qualifying factors. For example, most medical/dental procedures are foreseen with child and parent preparing both physically and mentally for the event. Children are routinely told that medical and dental personnel are good people with the child's best interest in mind. Likewise, such events usually have strong adult approval therefore reducing potential threat, fear and stress in the child. Ironically, studies have shown that the average levels of stress experienced by children in most of the studies (except those on VCUGs - Goodman et al, 1994; Merritt et al., 1994) were not high. All these taken together can conceivably influence and direct a child's recall.

Peterson (Peterson, 1996, 1999; Peterson \& Bell, 1996; Peterson \& Whalen, 2001) tries to provide a bridge between controlled, systematic investigation and ethical research of memory for traumatic occurrences by interviewing children shortly after they experience a minor injury. Using this procedure, children's amount and accuracy of recall of unforeseen stressful injuries over short and long-term delays can be determined. Although children's level of stress is admittedly not as high as in serious trauma, it may be higher than the stress experienced during medical/dental procedures (except VCUG procedures) because accidental injury usually causes significant physical pain in the 
absence of any type of adult reassurance. Such a design permits the ethical and systematic study of unanticipated, naturally occurring stressful events that mimics those events that would most likely be processed through the criminal justice system. The results of the Peterson studies $(1996 ; 1999$; Peterson \& Bell, 1996; Peterson \& Whalen, 2001) address an important and forensically relevant question: Do long retention delays have differential memory effects depending on the ages of children? More specifically, her results challenge the validity of the legal professional's long standing belief that long delays between incident and questioning heightens forgetting by young children (Flin, Boon, Knox, \& Bull, 1992).

In laboratory studies, interactions between age and the delay of interview on recall have consistently been found (see Brainerd, Reyna, Howe, \& Kingma, 1990). However, no age differences, with respect to recall, were found between 6- and 10-yearolds by Poole and White (1993), between 4- and 7-year-olds by Goodman et al. (1991) or between 5- and 10-year-olds by Warren and Swartwood (1992). Peterson (1999) examined memory of children in a wider age range (2-13 years old) and found little difference between 5- and 13-year-olds. The 3- and 4-year olds had significantly less recall compared to the 5-year-olds and the 2-year-olds remembered less than the 3 - and 4 year-olds. Therefore, it is the very young preschoolers that pose the particular difficulty for forensic interviews; however, as mentioned previously, 3-year-olds can accurately recall highly salient events (Peterson, 1996, 1999; Peterson \& Bell, 1996). Although the preschoolers' recall of target events was significantly lower than the school-age 
children's, what they did recall was accurate. Furthermore, preschoolers' recall of crucial events is high for a long time with children's information about pain-causing events (the injury itself and the hospital medical treatment) still almost invariably correct 6 months later.

Peterson (1996, 1999; Peterson \& Bell, 1996; Peterson, Moores and White, 2001; Peterson \& Whalen, 2001) has concentrated on investigating memory of young children over significant delays ( 6 months to 5 years). In all cases, children were recruited from the emergency room (ER) at a local children's hospital. Immediately after recruiting the child and parents for the respective study, the parents were contacted in order to schedule a time when an initial interview with the child could take place and the parents' reports were used as a baseline from which relevant details and accuracy could be assessed. This initial interview normally took place within a week following the injury. Then follow-up interviews occurred at 6 months (Peterson, 1996; Peterson \& Bell, 1996), 1 year (Peterson et al., 2001), 2 years (Peterson, 1999; Peterson et al., 2001), or 5 years (Peterson \& Whalen, 2001). Peterson and her colleagues found that memory changes with age such that older children recall more than the younger children; however they also discovered that children as young as 3 years old are recalling enormous amounts of detail and are surprisingly accurate. These findings are of forensic significance since an increasing number of young children are involved in the justice system and are not necessarily interviewed immediately after witnessing or experiencing an event by a 


\section{Influence of an Early Interview 9}

representative of the court. In fact, the delay between incident and questioning can range from days to years (Flin, 1993; Goodman et al., 1992).

Not only are children in forensic situations often questioned long after the target event occurred, they are also typically interviewed many times before they are actually required to provide testimony in court (Ceci \& Bruck, 1993). Repetition within the same interview will not be discussed since the data has been recently reviewed (Fivush, Peterson \& Schwarzmueller, 2002, Fivush \& Schwarzmueller, 1995; Poole \& White, 1995) and all authors concur that such repetition has serious negative effects on the consistency of children's reports. It has been suggested that even though children can give accurate accounts when questioned properly, their credibility is seriously undermined when inconsistencies appear between multiple interviews (Leippe, Mannion \& Romancyzk, 1991; Ross, Miller \& Moran, 1987). It has been shown that children's recall of events can change substantially across recall occasions, whether the recalls are separated by a few weeks (Fivush, Hamond, Harsch, Singer \& Wolf, 1991; Hudson, 1990) or several years (Fivush \& Hamond, 1990; Fivush \& Shukat, 1995). Likewise, Middleton and Edwards (1990) proposed the possibility of the fluidity of memories making them vulnerable to interference each time they are recalled. Although such results are noteworthy, researchers have demonstrated that simply asking children to recall an event again and again does not undermine their recall of those events as long as the questioning is not misleading, suggestive or coercive (Fivush \& Schwarzmueller, 1995). 
Theoretical reasons and supportive evidence suggest that repeated interviews on memory may be associated with increased accurate recall of relevant details of the event. Two mechanisms may be involved. First, an interview conducted shortly after the target event could essentially have a consolidating effect on the memory that will serve to buffer or "inoculate" against forgetting (Brainerd \& Ornstein, 1991; Brainerd et al., 1990; Fivush \& Hamond, 1989). The initial interview can serve as a partial re-exposure to, or reinstatement of, the original event (Brainerd \& Ornstein, 1991; Fivush \& Schwarzmueller, 1995) thereby increasing the accessibility of the original memory for subsequent retrieval (Hoving \& Choi, 1972; Howe, Courage, Bryant-Brown, 1993; Rovee-Collier \& Shyi, 1992). Second, organized, systematic questioning of events, timing, players, and places may also serve to coordinate and structure details in memory and, therefore, attenuate forgetting and facilitate subsequent recall (Fivush \& Schwarzmueller, 1995),

Differences in the amount and accuracy of information retained about traumatic events generally follow typical developmental patterns (Goodman et al. 1994, 1997; Ornstein, Baker-Ward, Gordon \& Merritt, 1997). Accordingly, interviews with children should be conducted as early as possible due to risk of memory fading. Moreover, children's errors may increase over time, even when the interviewer asks no misleading questions (Poole \& White, 1993). Therefore, if children are interviewed early, not only will details be more accurate, but the interview itself may reduce further forgetting, a phenomenon known as "inoculation against forgetting" (Brainerd et al., 1990). Warren 
and Lane (1995) corroborate this phenomenon and also propose attenuation of suggestibility with early questioning.

Others have reported positive effects of an initial interview when it occurs early, that is within days or a week of subsequent recall (e.g. Baker-Ward, Hess \& Flannagan, 1990; Fivush \& Hamond, 1989; Howe, 1991; Hudson, 1990; Tucker, Mertin, \& Luszcz, 1990; Warren \& Lane, 1995). For example, Fivush and Hammond (1989) found that those children who twice reenacted events, one reenactment shortly after the event, demonstrated more complete and accurate memories than those who reenacted it only at a later date. Similarly, Tucker et al. (1990) asked 5- and 6-year-old children to recall an immunization experience 1 to 7 days later. Those who were initially interviewed a day following the vaccination procedure recalled more details at a subsequent 1-week interview than those first interviewed after a 1-week delay. Finally, Hudson (1990) queried kindergarten children about a creative movement workshop in which they participated twice. Half of the children participated in the identical workshop at each time, while half participated in a slightly different workshop at each time. Some children recalled the workshop on the day of its occurrence and again after 4 weeks; other children recalled the workshop only after 4 weeks. Children in both workshop conditions recalled more information if they experienced both the immediate and delayed recall than children in the delayed recall only, and this held true regardless of workshop (i.e. identical or slightly different). 
Baker-Ward et al. (1990) found that 5- to 8-year-old children who were interviewed about an experience initially and after 3 weeks not only reported more information than children interviewed for the first time after 3 weeks, but the level of retention exhibited at the first interview was maintained throughout the 3-week retention interval. Furthermore, Fivush and Schwarzmueller (1995) indicate that the first recall may not have to be immediate to facilitate later memory. However, early questioning does not always facilitate later recall, especially when there is a lengthy interval before the second retrieval (Baker-Ward, Gordon, Ornstein, Larus \& Clubb, 1993).

Sutherland, Webster, Jones, LaRooy, and Pipe (submitted for publication) found that an initial interview could have significant positive effects on the amount and accuracy of long-term recall, but the effect of the initial interview depended on the timing of that interview. More specifically, delayed initial interviews had a positive long-term effect on the amount and accuracy of children's reports, protracting recall performance over the 2-year retention interval, whereas an early interview resulted in greater consistency in information across interviews. They re-interviewed 66 children who participated in an earlier Jones and Pipe (2002) study at 1 and 2 years. These children were 5 and 6 years of age when they participated in the novel, relatively non-stressful, structured event, "Visiting the Pirate". They were originally assigned to one of five initial interview groups: immediate, 1 day, 1 week, 1 month, or 6 months.

The findings of the Sutherland et al. (submitted for publication) study are consistent with predictions that memories may be re-activated within a time window of 
forgetting (Rovee-Collier, 1995; Rovee-Collier, Greco-Vigorito, \& Hayne, 1993) and that an initial interview will have greater effect when it occurs after a long delay, when retrieval is more effortful and the weakened memory must be re-activated (e.g. Hayne, 1990; Hudson \& Sheffield, 1998). Although the results are striking and can lend support to the credibility of delayed questioning, they still beg the question: What if initial questioning is delayed longer than 6 months? More specifically, would similar recall effects with respect to completeness and accuracy be reported in children whose initial interview was one year after the target event?

It is logical to query the accuracy of recall when formal questioning follows the traumatic event by a significant delay. Yet, this area of inquiry has received little attention despite its forensic relevance. The idea that early initial questioning may facilitate the consolidation of the memory has important theoretical implications in developmental psychology, but pragmatically, its applicability within the judicial setting is conceptual and unrealistic. That is, for those activities that involve testimony of children (suffering and/or witnessing abuse), formal forensic interviews usually occur following significant delays and thus early interviewing is often impractical. Recent research has discovered that children can remember significant amounts of details, over lengthy delays, with striking accuracy (Peterson \& Whalen, 2001; Quas et al., 1999); however can accurate recall be maintained in the absence of early interviewing? Although Sutherland et al. (submitted for publication) say 'yes' and contend that children remember more when the initial interview is delayed 6 months the target event was 
relatively non-traumatic. Even though 6 months is a fairly significant delay for first-time questioning, a longer delay would increase the forensic relevance of such results since not all criminal cases concerning children may come to light early after an experienced or witnessed event. It is therefore necessary to evaluate whether lengthy delays, in excess of 6 months, would significantly impact accurate recall of traumatic events.

There were two goals of the present study. One analysis was directed to investigate whether or not having an early initial interview would influence long-term recall of traumatic events. The second analysis was geared towards evaluating the effect of multiple interviews on long-term recall of traumatic events. Most researchers agree that children have good memory of traumatic events over long delays and it has been argued that an initial interview aids in consolidation of memory and subsequently inoculates children against forgetting (Brainerd et al. 1990; Fivush \& Schwarzmueller, 1995; Rovee-Collier \& Shyi, 1992). The purpose of this study was to clarify the dynamics of that memory by evaluating the influence of an early initial interview on accurate recall of the traumatic event a year later and to assess whether retention is augmented by the number of interviews a child participates in.

The memory retention of children who were interviewed shortly after the traumatic event would be compared to those who were initially interviewed a year following the event. By examining children's memory for naturally occurring injuries that were serious enough to require emergency treatment, trends in memory completeness and accuracy of highly salient events can be scrutinized. Despite the events being 
personally relevant and thought to be not easily forgotten, it is uncertain whether those memories would still be elicited and to what degree of accuracy if an initial interview immediately after the traumatic incident did not occur. More specifically, would recall of memories be as complete and accurate in the absence of early questioning?

The present research is an adoption of Peterson and Bell's (1996) methodology instead of children receiving an initial interview within a few days of their injury, their first interview was delayed for a year. Baseline information was obtained from the parent and whoever was present and/or witnessed the injury. The aim was to adequately examine whether children can still remember significant amounts of detail of salient, personally experienced events when not immediately questioned about them in a highly structured way. The present study incorporated the accepted policy on questioning by having mostly free recall and open-ended questions. The interview was highly structured and methodical in detail, asking children specific questions about location, actors, timing and emotional aspects of injury and surrounding events. For the purposes of analysis the information provided by the parents and children were separated into two groups: injury information and hospital information. It was hypothesized that the traumatic events examined in the present research would be remembered regardless of early initial interview. More specifically, it was thought that children's memory for their injury and occurrences surrounding that injury would not be impaired by the absence of an initial interview shortly after the event, and subsequent recall amounts and accuracy of relevant details would be similar to previous studies using this methodology. 
Three age groups were used as well as three different cohorts were used in the present research. The choice in age groups (3- and 4-year olds, 5-7 year olds and 8- and 9-year olds) reflect previous findings that these ages represent fundamental differences in amount and accuracy of recall (Peterson, 1999; Peterson \& Bell, 1996). The cohorts represent children recruited for the present study plus two comparison groups taken from previously collected data, all of which were recruited, interviewed, and scored by different people at different times. The children most recently recruited had their initial interview one year after the injury; another group, whose recall completeness and accuracy were collected prior to the present study, contained children who were interviewed twice, once immediately after the injury and again one year after. These children were used in Peterson, Sales and Fivush (unpublished). The final group of children had three interviews, one immediately after, one at six months, and the third at one year post-injury. The immediate and 6 month results are published in Peterson and Bell (1996) and the 12 months data in Peterson (1999). These comparison groups were necessary to adequately analyze the influence of long delays between event and subsequent questioning on recall amount and accuracy. It was essential to have a group that had no significant delay between target event and questioning as a comparison. The comparison groups were also necessary for considering the potential influence of multiple interviews and repetition on recall amount and accuracy.

Recruitment for all three groups spanned 6 years. The authors acknowledge that differential recruitment presents confounds such as children injured in different years, 
variation in treatment personnel at hospital, different recruitment personnel, and different people scoring data. However, it was judged that such confounds did not pose a significant threat to the reliability and validity of results since interviewers were rigorously trained by the same person (Peterson) with the interview protocol remaining unchanged. The supervisor of recruitment and interviewing has been the same throughout the collection of data and periodic and consistent testing of interviewers is a requirement of the interviewing process. In addition, the person who reads all the transcripts and trains people in scoring data has also remained the same across the entire collection of children.

The director of the emergency room (ER) where the children were recruited has also remained stable across the years of the data collection. In the ER, whether within the same time frame of recruitment or not, there is always considerable variation in who treats the children, particularly because residents and interns rotate through the ER regularly. Of most importance is that the supervising staff has remained constant. Ultimately, there have been no major changes across cohorts. The selection of children treated at the hospital as well as the catchment area (i.e. geographical location of subjects used with all three recruited groups) has remained the same throughout recruitment for all three groups. 
Influence of an Early Interview 18

Method

\section{Participants}

Sixty-two preschool and school-aged children were recruited from the emergency room (ER) in the Janeway Hospital, St, John's, Newfoundland. This facility is the only exclusively children's hospital that services all children in Newfoundland from birth to age 16 years inclusive. The sample was of mixed socio-economic status (SES), mostly white, and resided in nearby cities or surrounding communities. The children had experienced what were considered trauma injuries (since they involved more than a visit to their family doctor) that necessitated a visit to the ER. Injuries included broken bones, lacerations requiring sutures, dog bites, and burns. All children received outpatient care and were subsequently released from hospital.

At the time of injury, the children were between the ages of 3 and 9 years inclusive. The ages were split into 3 specified groups: 3 - and 4-year-olds (Mean age: 3 years 8.5 months, Range: 2 years 11.5 months to 4 years 11.5 months), 5 - to 7 -year-olds (Mean age: 6 years 4.5 months, Range: 5 years 2 months to 7 years 11.5 months) and 8 and 9-year-olds (Mean age: 9 years 1 month, Range: 8 years 2 months to 9 years 9.5 months) with 18,17 , and 18 participants in each group respectively. Of the 62 parent (initial) interviews, 53 child (one-year follow-up) interviews were conducted. Five of the parents could not be reached, one moved to another province, two of the children did not wish to participate and one of the tape recordings was incomplete. 
A total of 88 interviews from previous samples, collected in the same manner as in the present study, were used in comparisons. There were two comparison groups: one had an initial interview and another one year after injury ( 0 and 12 months); the other group had an initial, a 6-month and a one-year follow-up interview (0,6 and 12 months). Comparisons were made to evaluate children's long-term memory for those who had only one interview (present study) versus those that had two ( 0 and 12 months) and three interviews $(0,6$ and 12 months). The data were compiled to match the age groups delineated in the present study, and to facilitate analyses, the same numbers of participants were randomly selected to match each age group.

For the 0 and 12 months group, 8- and 9-year-olds were not recruited. For analyses involving this comparison group, only two age groups were used: Eighteen 3and 4-year-olds (Mean age: 3 years 9.5 months, Range: 2 years 6 months - 4 years 11 months) and seventeen 5- to 7-year-olds (Mean age: 5 years 8 months, Range: 5 years 2 months - 6 years 10 months). The 0,6 and 12 months group included all three age groups: Eighteen 3- and 4-year-olds (Mean age: 3 years 9 months, Range: 3 years 2 months - 4 years 9 months), seventeen 5- to 7-year-olds (Mean age: 5 years 9 months, Range: 5 years 4 months -6 years 11 months), and eighteen 8- and 9-year-olds (Mean age: 8 years 8.5 months, Range: 8 years -9 years 11 months). See Table 1 for a listing of sample size, mean age and range of age for each age group according to their number and timing of interview(s). The total numbers of subjects for the 0 and 12 months group and 
Influence of an Early Interview 20

the 0,6 and 12 months group were 35 and 53 respectively for a grand total of 141 children in the entire study.

\section{Procedure}

At the time of initial recruitment, all families of injured children who were of the appropriate ages were approached in the ER and asked to be part of a long-term study of children's memory of traumatic events. The study was briefly described, informed consent forms were signed and permission for telephoning was established. The majority of families agreed to participate ( $81 \%)$.

The first visit entailed only an interview with the parent. The interviewing techniques were the same for both parent and child interview (see below). It took place either in the homes of the children or at a location that was comfortable for the parent. This interview usually took place within a couple of weeks of the injury (Median delay (days) $=12$, range $($ days $)=2-58$ ) and lasted approximately 20 minutes. For some injuries, a parent was not a witness and thus relevant other witnesses were interviewed. Initial permission for such interviews was given by the parent(s). These included daycare workers, cousins, and siblings. However, a parent was always a witness to hospital treatment and therefore always interviewed. The information obtained from the parent and other relevant witnesses in the initial interviews provided a baseline from which to evaluate the accuracy of child interviews. The children were interviewed approximately one year from the date of their injury (Median delay (days) $=11$, range (days) $=$ $27 \rightarrow+53$ ). The minus sign refers to days prior to one year after the original injury date 
and the plus sign refers to those dates taken after the original injury date anniversary. No child in the most recently recruited sample was questioned about their injury until at least 11 months later.

For the comparison groups the initial interview included an interview with both child and parent and, if necessary, other relevant witnesses. Since these children were to be questioned immediately following their injuries both interviews were obtained in one visit. Similar to the more recently recruited sample, the interviews usually took place within a week or so of the injury ( 0 and 12 months group: Median delay (days) $=7$, range $($ days $)=2-42 ; 0,6$ and 12 months group: Median delay (days) $=6$, range $($ days $)=1-22$. The one-year follow-up interview for the 2-Interviews Group (at 0 and 12 months) took place within approximately two weeks from the original injury date (Median delay (days) $=12$, range $($ days $)=9-16$ ). The 3-Interviews Group had their follow-up interviews six months (Median delay (days) $=6$, range (days) $=5-9$ ) and one year after injury data $($ Mean delay $($ days $)=11$, range $($ days $)=10-14)$

For return visits (i.e., child interviews) the same interviewing technique as with the parent was used. For the children recruited for the present study and the comparison groups, only the child was interviewed at this time. When contacted to schedule the child interview, parents were asked not to discuss or rehearse the incident with the child prior to the visit. Rapport was first established between interviewer and child and then the interview was conducted. The interview was extensive and organized, asking children to recall events surrounding the injury, subsequent treatment and pre- and post-ER events. 
The interview began with free recall ("Tell me about your injury." "Tell me about what happened at the Janeway Hospital.") where the interviewer tried to engage the child in more discussion simply by nodding her head and saying "Tell me more", "Yeah?" and "Really?" Free recall was then followed by probed recall using wh-questions ("What happened? Where were you when it happened? What did you do when you first got hurt? Who was there?'). In all interviews yes/no questions were avoided as much as possible. However, if relevant information had not been obtained already yes/no questions were asked but they were only done to encourage more detail (e.g. "Did it bleed? Did you cry?). Because relatively few yes/no questions were asked and the responses are suspect (Peterson \& Biggs, 1997; Peterson, Dowden \& Tobin, 1999), responses to these questions were not analyzed further. A detailed list of queried items is found in Appendix A. The list provides examples of questions that target the desired information which in turn represent the categories of scoring as well as providing a chronological review of the sequence of an interview.

If children provided information about a specific element in free recall, they were not also asked about it in probed recall. Similarly, children who provided information in response to a wh-question were never asked a yes/no question about it. This questioning procedure was chosen in light of concerns raised about the effects of repeated questioning to elicit the same content (Fivush \& Schwarzmueller, 1995). Interviews were audiorecorded and transcribed verbatim with all scoring done from transcripts. In situations in which the child responded non-verbally to a 'how much' question (e.g. "How much did it 
bleed?" and the child held up 5 fingers), the interviewer would ask them if that meant "a little?" or "a lot?" If the child pointed to the part of their body that was injured then the interview would simply state the child's action for the tape recorder (e.g., "You are pointing to you left wrist'), and these responses would be counted as the child providing a content response. The average duration of a child interview was 30 minutes and would vary with age.

The procedures used in the present study were modeled closely after those used by Peterson and Bell (1996) and were used exclusively in the gathering of all data used in this investigation regardless of time collected. The study was described and signed consent was obtained at initial recruitment and at the first home visit, as approved by the Memorial University of Newfoundland Faculty of Science Human Research Ethics Committee and the Faculty of Medicine Human Investigation Committee (See Peterson, (1999) and Peterson \& Bell, (1996) for reports on children's memory of these events.) Consent by both the parent (written) and child (oral) was required for all visits including both child and parent/witness interviews.

Scoring of Recall Data

Even though all children experienced a personally unique injury and hospital treatment, they all resemble a prototypical pattern that included various components from both injury and hospital treatment. Many prototypic items included in the scoring were applicable to all children (e.g., place where injury occurred, who brought them to the hospital), while others applied only to a subset of children (e.g., getting a cast, having a 
needle). The prototypic items that applied to each child were determined from inspecting the parent transcripts. The prototype classification and examples of each item are shown in Appendix A. This classification was used in scoring the amount of items recalled as well as their accuracy. Because there was variation in how many prototypic elements applied to individual situations, different children had different numbers of "scorable" items that were relevant to them and thus could potentially be present in their recall of each of the two events (i.e., injury and hospital treatment). Previous research shows that children vary substantially in their completeness and accuracy of recall with respect to the injury and its treatment. More specifically, the details of the injury are recalled more completely and with greater accuracy than those of the treatment procedure (Peterson, 1999; Peterson \& Bell, 1996). In keeping with these results, the present analyses also divided "scorable" data into these same two categories: injury details and treatment details.

All prototypic items were classified as pertaining to the injury or hospital treatment and total counts for each category were taken. Total recall counts included responses from free recall and probed recall portions; responses to yes/no questions were not scored. For example, if a child started by saying that they hurt their wrist and later, once the interviewer started asking more probing questions, says it again, that specific item was counted only once. It was also counted as one bit of information if the child provided it in free or probed recall (wh-questions). To assess trends in spontaneous recall of information over numerous interviews, a separate free recall count was also 
obtained. This differed from total recall by isolating and counting only information given without being probed (usually at the beginning of the interview with the question "What happened when you hurt yourself?") regardless of whether it was also given later in the interview.

After determining which components of the prototype applied to each child, the child's transcripts were searched to determine, first, whether the child supplied information relevant to each prototypic component in each interview. If such information was provided, it was then compared with the information provided by adult witnesses in order to assess accuracy. The coding of "accurate" was not only given for complete agreement between child and adult responses, but also for close approximations. For example, if the child said that they injured themselves around lunchtime and the parent/witness indicated that the time of the injury was around 1:00 p.m., the child was credited with an accurate response. Also children who misstated the number of stitches or X-rays were not credited with an error if they had correctly said that they in fact had stitches or X-rays. In rare cases, children provided information that was not commented on by witnesses; in such cases the data were excluded from the analyses. To establish reliability, two raters scored $15 \%$ of the transcripts, and agreement on recall completeness and accuracy averaged $95 \%$. 
Influence of an Early Interview 26

The following sets of data were analyzed:

Completeness of memory

The completeness of the child's recall about emotionally salient events regarding the injury and subsequent treatment were evaluated. This analysis was directed toward answering the question "How much of what happened does the child accurately remember?" The completeness of a child's recall of each category was calculated by dividing the number of component items correctly recalled by the number of component items that were relevant for that child according to the parental account and thus could potentially have been recalled. This proportion of recalled relevant components was presented separately for the injury and hospital treatment events. Proportions were calculated for both total recall scores and free recall scores.

Accuracy of memory

The accuracy of the children's recall was determined by dividing the number of correct prototypic components by the number of relevant components the child provided. This analysis was directed at answering the question "How much of what they do say is accurate?" Thus, instead of using the possible components that children potentially could have recalled as the denominator (as in the analysis of completeness of memory), the actual components that the child did remember were used. In this analysis, only commission errors were counted, that is, instances in which a child stated information that was explicitly contradicted by the adult witness's report. The number of commission errors about prototypic components was counted for each episode of injury and hospital 
treatment separately and the percentage proportion correct of the actual prototypic components that had been provided by the child were calculated.

\section{Results}

Previous research has shown that children have extensive recollections about details of their injuries and treatment even over long-term delays. Although it is accepted that children can remember injury and hospital details over lengthy delays it is important to determine whether the completeness and accuracy of their recall are a product of the timing of their first interview or of how many times they have been questioned on those events. In the present study, because data for a specific age group (8- and 9-year-olds) for the 0 and 12 months group were not available, the evaluation of the influence of number and timing of interviews on specific ages had to be calculated using two separate mixed analyses of variance (ANOVA) for each of the completeness of memory and accuracy scores (resulting in four separate ANOVAS). There were three interview groups: 1-interview group whose interview was done 12 months after the target event (12 months group); the 2-interview group whose interviews took place shortly after the injury and again at 12 months ( 0 and 12 months group); and the 3-interview group who were interviewed shortly after the target event, at 6 months and again at 12 months $(0,6$ and 12 months group). The ages were divided into three groups (3- to 4-, 5- to 7- and 8- to 9year-olds). These analyses were done for both total recall and free recall scores resulting in a final total of eight mixed ANOVAS. 
The analysis was performed in two ways. First, a comparison of all three age groups was conducted using a mixed ANOVA with age ( 3 levels), and number and timing of interviews ( 1 vs. 3 ) as the between participants variable and event (injury vs. hospital) as the within participants variable. (Note that in this and other analyses that include the variable of age, the data were coded for age groups, i.e., age was not treated as a continuous variable.) Second, another comparison of the two younger age groups (3to 4-year-olds and 5- to 7-year-olds) over all three interview levels was done, using a mixed ANOVA with age ( 2 levels), and number and timing of interviews ( 3 levels) as the between participants variable and event (injury vs. hospital) as the within participants variable. These comparisons were designed to isolate the impact of the frequency and timing of interviews. Preliminary overall analyses were completed including gender, but no significant effects were found. Gender was, therefore, excluded from further analyses.

\section{Total Recall Scores}

\section{Completeness of memory.}

To examine the effects of frequency and timing of interviews on the completeness of children's long-term recall, the memory performance of the three interview groups in their one-year interviews was compared. Table 2 includes the mean percentages and standard deviations of children's completeness of memory for total recall. Children in all interview groups showed extensive recollection of the event at their one-year follow-up interview. When all three age groups were compared across the two levels of interviews (12 months and 0,6 and 12 months) it was found that children recalled a greater 
Influence of an Early Interview 29

percentage of relevant detail about the injury $(M=73.5 \%)$ than the hospital treatment ( $M$ $=54.9 \%) F(1,100)=125.77, p<.001$. There was a significant main effect of age, $F(2$, $100)=26.34, p<.001$. Planned comparisons revealed differences between the youngest children $(\mathrm{M}=53.8 \%)$ and both of the older two groups $(\mathrm{Ms}=68.2 \%$ and $70.1 \%$ respectively), which in turn did not differ from each other. There was an Age $X$ Interview interaction, $F(2,100)=5.13, p=.008$, shown in Figure 1. Follow-up analyses were done on each age group separately to assess whether the number and timing of interviews affected memory completeness. The number and timing of interviews was significant for the youngest children, suggesting that having an initial and 6 month interview can make a notable difference in how much relevant information is recalled by 3- and 4-year-olds. For the older two groups, completeness of recall was equivalent regardless of the number and timing of interviews. Thus, the frequency and timing of interviews influenced the youngest, but not the older children.

The above analysis compared all three age groups but only two levels of interview were included. In the next analysis 3- and 4-year olds and 5- to 7-year-olds only were compared across all three levels of interviews. Three main effects were obtained: (a) Similar to the above analysis children recalled more about the injury $(M=69.9 \%)$ than the hospital treatment event $(\mathrm{M}=50.5 \%), F(1,99)=120.73, p>.001$. (b) Children recalled more as they got older, $F(1,99)=17.06, p<.001$. The older children recalled more $(M=65.5 \%)$ than the younger children $(M=55.0 \%)$. An Age $X$ Interview interaction only reached borderline significance, $F(2,99)=2.89, p=.061$, as shown in 
Figure 2, but it followed a similar pattern as that displayed in Figure 1. Follow-up analysis for each age group separately showed a significant effect of interview only for the youngest children. (c) Children remembered more the more interviews they had, $F(2$, $99)=3.61, p=.031$. Means equaled $57.1 \%, 58.6 \%$ and $64.9 \%$ for the 12 months, 0 and 12 months, and 0,6 , and 12 months groups respectively. By using planned comparisons it was found that recall differences as a function of frequency and timing of interviews were significant $(p=.002)$ only between the 12 months group and the 0,6 and 12 months group with the 0 and 12 months group intermediate and not differing significantly from either other group. This is suggestive of a developmental progression with children remembering more with more interviews.

Accuracy of Memory.

The proportion of information recalled accurately by the child was analyzed using the same comparisons as in the above analyses. Children in all interview groups were quite accurate in their recollection of the event at their one-year interview. Table 3 presents the mean percentages and standard deviations for accuracy of total recall. Using the same analysis as with completeness of memory, a comparison of all three age groups over only two levels of interviews was used to evaluate the accuracy for total recall. Two significant main effects were found: (a) Children were more accurate when recalling injury events $(\mathrm{M}=87.9 \%)$ versus hospital treatment details $(\mathrm{M}=82.1 \%), F(1,100)=$ $18.12, p<.001$. (b) Children were more accurate as they got older, $F(2,100)=11.10, p$ $<.001$. Mean percent correct recall was $81.5 \%, 86.3 \%$ and $89.9 \%$ for ages $3-$ to $4-, 5$ - to 
Influence of an Early Interview 31

7-, and 8- to 9-year-olds respectively. Planned comparisons revealed a significant difference between the two younger groups (3- to 4-year-olds and 5- to 7-year-olds) but not between the 5- to 7-year-olds and the 8- to 9-year-olds. There was no significant effect of the number and timing of interviews on children's accuracy either as a main effect or an interaction with age.

Parallel to the second analysis performed on the completeness data, a second analysis was made of the accuracy scores. Only two age groups were compared (3- to 4year-olds and 5- to 7-year-olds) over all three interview levels. In this analysis, the number and timing of interviews did have a significant effect, $F(2,99)=3.33, p=.040$. Using planned comparisons, it was shown that accuracy was equivalent for children who had one (12 months) and two interviews ( 0 and 12 months) $(\mathrm{Ms}=79.6 \%$ and $77.6 \%$ for one and two interviews, respectively) and children in both groups were less accurate than children with three interviews $(0,6$, and 12 months $)(M=85.4 \%)$. These results appeared inconsistent from those found in the completeness of memory analysis and thus need to be put in context. Firstly, the mean accuracy was high for all interview levels with the lowest average being $77.6 \%$, suggesting that children were already quite accurate regardless of frequency and timing of interview. Secondly, the non-significant effect of interview with only two levels included (12 months, and 0,6 and 12 months) compared with the significant effect of interviews with three levels of interviews included (12 months, 0 and 12 months and 0,6 and 12 months) indicate a skewing effect caused by the 8- to 9-year-old age group which are omitted when the analysis includes all three 
interview levels. It appeared that this group, being so accurate, had raised the average and essentially influenced a non-significant result when only two levels of interview were used versus when all three levels were included.

There were two other main effects in this analysis. Older children $(M=83.3 \%)$ were more accurate than younger children $(\mathrm{M}=77.9 \%), F(1,99)=5.43, p=.022$. As well, children were more accurate when recalling the injury $(\mathrm{M}=85.8 \%)$ than the hospital event $(\mathrm{M}=79.2 \%), F(1,99)=15.7, p<.001$. There were no interactions.

Free Recall Scores

Not all children provided information in free recall. For details on the number of children failing to providing free recall information see Table 4 . This affects the $d f$ in the analyses presented below.

\section{Completeness of Memory.}

To analyze possible patterns of rehearsal effects free recall scores were considered separately. These analyses were identical to those performed on total recall scores and isolated age and interview effects on children's completeness of memory and accuracy. Children were less complete in their recall using only free recall data, as can be seen in Table 5 which presents mean percentages and standard deviations for completeness of free recall. When using all three age groups across only 2 levels of interview there were three main effects: (a) Children remembered more about the injury $(\mathrm{M}=34.4 \%)$ than the hospital treatment $(\mathrm{M}=20.4 \%), F(1,88)=68.88, p<.001$. (b)

The older the child the better the recall of relevant details $F(2,88)=17.37, p<.001$. The 
results from planned comparisons indicate a consistent progression with 3- to 4-year-olds $(M=18.3 \%)$ recounting less in free recall than 5- to 7-year-olds $(M=26.7 \%)$ who in turn recalled less that 8- and 9-year-olds $(M=37.2 \%)$. (c) The more interviews the more complete the memory $F(1,88)=4.35, p=.04$. Mean percent recall for 1 and 3 interviews was $24.6 \%$ and $30.2 \%$ respectively. There were no significant interactions.

For the analysis that included all interview levels but only the two youngest age groups (3- to 4-year-olds and 5- to 7-year-olds) a similar pattern emerged. Children spontaneously recalled more about the injury than the hospital treatment, $F(1,76)=59.99$, $p<.001$ with corresponding means of $28.8 \%$ recall for injury and $15.0 \%$ for hospital. An age effect was found, $F(1,76)=10.99, p<.001$, with the 3 - to 4 -year-olds $(M=17.9 \%)$ recalling less that the 5- to 7-years-olds $(\mathrm{M}=25.2 \%)$. There was also an Interview effect, $F(2,76)=3.37, p=.040$. Planned comparisons revealed a significant difference in free recall between one (12 months) and three ( 0,6 and 12 months) interviews while the 0 and 12 months interview group did not differ significantly from either other group (Ms $=19.1 \%, 21.0 \%$ and $25.9 \%$ for the one (12 months), two ( 0 and 12 months) and three ( 0,6 and 12 months) interview groups, respectively). There were no significant interactions.

\section{Accuracy of Memory.}

Accuracy scores in free recall for all age groups over all levels of interviews were impressively high as can be seen in Table 6 which presents mean percentages and standard deviations of accuracy for free recall. For all three age groups, compared over 2 
interview levels, children recalled both the injury $(M=97.6 \%)$ and hospital treatment ( $M$ $=95.0 \%)$ with similar accuracy, $F(1,88)=1.93, p=.17$. In addition, there was no effect of age, $F(2,88)=.45, p=.64$, or interview, $F(1,88)=1.14, p=.29$ on free recall accuracy using all three age groups.

When analyzing only the 3- to 4-year-olds and the 5- to 7-year-olds across all three interview (12 months; 0 and 12 months; 0,6 and 12 months) levels the results were similar. Both groups displayed similar accuracy when recalling injury and hospital treatment details, $F(1,76)=2.88, p=.09$. Also, neither group differed significantly from one another on age, $F(1,76)=.01, p=.92$ or interview, $F(2,76)=.47, p=.63$. Although completeness scores may have been lower than with total recall, overall, it did not matter how old the child was or whether they had been interviewed 1,2, or 3 times on their free recall accuracy scores; they all did exceptionally well.

\section{Discussion}

Public discourse surrounding the increased involvement of young children in the criminal justice system has had a significant impact on developmental research. Interest and action fuelled by reparation have prompted increased involvement of people in the judicial system either as victims, defendants, coconspirators, bystanders and now researchers. Changes in attitude and legislation have sparked new pedagogical interest in adjusting and fine-tuning criminal proceedings regarding credible testimony to reflect the developmental realities of children. One of the benefits of the upsurge in public concern about child witnesses, especially in child sexual abuse cases, is a renaissance in research 
about the reliability of children's memories. Within the past 20 years, there has been an explosion of scientific study of the cognitive capabilities of children, as well as of the social, emotional, and moral influences that might affect a child's reliability (Ceci \& Bruck, 1993, 1995; McGough, 1994).

Children involved in the justice system may not only have to recall details of events possibly long after they have occurred, but may also have to recount those details over and over again. Delayed questioning compounded by multiple interviews thereafter may seriously affect how much the child remembers and markedly influence the potential accuracy of those reported details. Thus, the influence of multiple interviews and subsequent timing of those interviews has great theoretical significance. Because age has been extensively reviewed in previous studies, the present study focused on two other important issues regarding young children's memory. This inquiry reflects the procedural reality of the criminal justice system. Firstly, can young children remember and recount complete and accurate memories of an incident if they are questioned long after the event? Secondly, can multiple interviews at various times enhance children's recollection of traumatic events?

The results reported here indicate that overall children have extensive recollection of details concerning the target event. All children have comprehensive recall of details but, as predicted, this was a function of age. The youngest children in the study (3- to 4year-olds) provided a remarkable amount of detail, at least about the injury event, with exceptional accuracy, but that was eclipsed by the significant effect of age, which 
revealed the superior memory of the older groups. Most of the detail remembered by the younger children was elicited through probed recall; however these young children still recalled the central points of the incident with surprising accuracy. Therefore, there was an age effect when using total and free recall to analyze the completeness of their recall.

In all age groups, the content being recalled made a significant difference. Whether they gave the information in free recall or probed recall, children were found to recall more details concerning the actual injury than the hospital treatment. Successful recollection of personally salient events with accuracy is quite typical (Baker-Ward et al., 1995; Goodman et al, 1994; Peterson, 1996, 1999; Peterson \& Bell, 1996; Vandermaas, Hess \& Baker-Ward, 1993); however, other factors, including the comprehensibility of the events, have also been implicated in the accuracy of recall (Bruck et al., 1995; Salmon \& Pipe, 1997; see Peterson, 2002, for a review). For example, Salmon and Pipe (1997) in a quasi-medical play event asked children 3-5 years of age to examine a "sick" teddy and found that there was considerable forgetting of the event over a year. Unlike the Peterson studies, these were not real medical events, and although Rudy and Goodman (1991) say that participation is not a necessity for long-term recall, these quasimedical events were probably not very personally salient to the child, nor did they make logical sense to them. In the present study the difference in content recalled was evident in all interview groups such that having 1,2 or 3 interviews did not influence the type of details prominently recalled. Also, content recalled did not affect the typical age trend whereby older children usually remember more that the younger children 
With respect to the proportion of details recalled, frequency of interviews is thought to play a critical and significantly positive role in subsequent recall (Fivush \& Hamond, 1989; Fivush \& Schwarzmueller, 1995; Tucker et al, 1990). The present findings however provide an indication that children could recall significant details in the absence of multiple interviews regardless of timing. Complete and factual recall by the older children ( 5 to 9 years of age) was not affected either positively or negatively by having multiple interviews at various times. Nor were these school-aged children's recall influenced by having an early initial interview. This result is inconsistent with research that suggests that an early initial interview can act to maintain the memory in an active state, inoculating the memory from the deleterious effects of forgetting (Brainerd \& Ornstein, 1991; Fivush \& Schwarzmueller, 1995; Fivush \& Hamond, 1989; Hudson, 1990).

The proposed influence of an early initial interview did, however, have a significant influence on the completeness of recall for the youngest group (3- to 4-yearolds). More specifically, there was a significant interaction between age and number of interviews such that the 3- to 4-year-olds' recall, as opposed to the 5- to 9-year-olds' recall, was positively affected by the early interview. In this respect our findings agree with Fivush and Schwarzmueller (1995), Fivush and Hamond, (1989), and Tucker et al. (1990) when they propose that younger children may depend on an adult's guidance for structuring their recall of events and subsequent memory. They insist that children do not rely on adults to provide the content of those recounts, but rather assist in their 
organization. This one-time "scaffolding" or monitored guidance supports Vygotsky's (1934/1986) notion that adults have an important role in fostering skill development. Vygotskian (1934/1986) theory has been implicated in the formation of narratives (Peterson, Jesso \& McCabe, 1999; Peterson \& McCabe, 1992; McCabe \& Peterson, 1991) and accordingly has implications for social aspects in the development of language. While the social aspect of adult-influenced memory development is a recent concept, current research has documented the positive relationship between language skill training on remembering (Boland, Haden \& Ornstein, submitted for publication; Leichtman, Pillemer, Wand, Koreishi, \& Han, 2000).

Leichtman et al. (2000), for example, studied 4- and 5-year-olds that had experienced a surprise event in their classroom - a visit from their former teacher and her new baby. Their mothers, who had not been present and were naive to the details, interviewed their children the same day about the event. Mothers were not trained to question them in any particular way, but it was discovered that those mothers who were more elaborative in their questioning influenced the amount of information provided by the child 3 weeks later. These authors suggest that parent-child memory talk can boost children's long-term memory reports even when parents do not share in the event or have no knowledge of its details. Similarly in the present study, the fact that 3- and 4-year olds retained and subsequently recalled significant amounts of factual details one year after the injury may reflect the highly structured, elaborative interview process. More specifically, it can be considered that a well-structured and extensive interview was 
enough to assist in the organization of the memories of 3- and 4-year-olds and potentially buffer those memories against forgetting a whole year later. Thus, it is plausible to suggest that memory has a social aspect to its development whereby young children's memory could be influenced and possibly partially developed through adult intervention.

In another recent study, mothers were actually trained in elaborative conversational style. The researchers hypothesized that such a style would enhance a child's understanding and memory of an event (Boland, Haden \& Ornstein, submitted for publication). Thirty-nine preschoolers were pre-tested for language skills and assigned to either a group whose mothers received maternal conversational style training or those who did not. The children of mothers with training demonstrated more elaborative and embellished recall than did children of untrained mothers. As a result, these researchers are suggesting there is a link between the social world and memory. If this is the case, then why were the older children not affected?

A possible reason may be found in Peterson and McCabe's (1983) study of preschoolers and school-aged children's narratives. They identified several narrative styles and studied children's narrative changes from 4 to 9 years of age. Three styles are relevant here: (a) Leap-Frog which is the most common pattern found among 4-year-olds where the child jumps unsystematically from event to event; (b) impoverished, another common pattern among 4-year-olds, where children concentrate on only a few action descriptors to the point where there is not enough to form a recognizable pattern; (c) disoriented which is also most common at the younger level and simply implies that 
narratives are contradictory and often reflect the child's confusion and/or difficulty with language. It was found that preschoolers would, by the time they reach 5 years of age, eventually learn the proper structure when forming narratives. The same could be said for memory of autobiographical events, which could essentially be considered a narrative. Thus, children typically learn through natural maturation and social development how to organize causal and temporal relationships, how to provide orientation of actors and to sequence events so as to construct a meaningful representation of an event; this in turn may well support and enhance memory. The older, school-age children, in most cases, have already learned this structure. The lack of significant interview effects for the older groups of children (i.e., 5- to 7-year-olds and 8to 9-year-olds) found in the present study is consistent with this possibility. The assistance with organization and structure seems to have its biggest influence when children are just learning this skill, that is, around 3 and 4 years of age.

The idea of internalized structure is also evident when analyzing the child's completeness of memory for those responses given in free recall. What is recalled in free recall may not necessarily be a good indication of memory but rather may be an indication of what a child thinks the interviewer wants to hear, a purely social assessment. Although the amount of information mentioned in free recall was somewhat sparse compared to total recall, albeit accurate, it was significantly influenced by whether or not there was an early initial interview. The effect of the early initial interview on completeness of memory in free recall was only evident, however, with the 3- to 4 year- 
old group. It can therefore be assumed that a highly structured interview early after the event not only assists preschool-aged children in the organization of memory but may also allow them to essentially learn what is expected from them in future interviews. Therefore, those preschoolers who had an early interview would have become adept at the "rules of recall" and have incorporated the sequence of questioning and expectation of answers to guide their recall in subsequent interviews.

The present results not only highlight the significant influence of an early initial interview but also emphasize the lack of effect of multiple interviews. It was found that having repeated interviews did not have any real impact, for any age, on what was recalled and this was supported by the non-significant effect between two versus three interviews. Rather, the timing of the initial interview was the critical issue. The results provided an indication that, at least for school-aged children, having 1,2 or 3 interviews by one year did not lead to a positive or negative shift in school-aged children's recall of relevant details regardless of the timing of the initial interview. This finding agrees with Fivush and Schwarzmueller's (1995) view that the initial interview need not be immediately after the target event(s) for benefits to occur, but only in part. The 3- to 4year-olds in our study, however, did not follow this pattern.

In keeping with Fivush and Schwarzmueller's (1995) premise, Sutherland et al. (submitted for publication) concluded that the timing of the initial interview could actually affect subsequent recall and that the later the initial interview, the better the recollection. They reported that there was increased recall at one and two years 
following the incident when the initial interview was delayed 6 months. The present results concur with Sutherland's et al. (submitted for publication) findings that timing of initial interview makes a difference; however the findings were in reverse. It was found that when the initial interview was shortly after the target event the better the recall a year later but only for the preschool children (i.e. 3- to 4-year-old group). Since their study did not include preschoolers it is difficult to predict whether or not children younger than 5 years old would have benefited from an early initial interview as they did in this study. In the present study when the older groups (5- to 7-year-olds and 8- to 9-year-olds) were compared there were no significant differences found in total recall or accuracy regardless of the timing of the interview. This stands in contradiction to Sutherland's et al. outcome. In light of these findings, it would be academically beneficial and legally instructive to explore the results from a 2-year follow-up interview conducted on the older children in the present study to compare whether early initial interviews can positively influence recall more than delayed initial interviews.

The study conducted by Sutherland et al. (submitted for publication) provided little support for a consolidation of the memory by an early interview. The present research, on the other hand, does support proponents of a consolidation account (Brainerd \& Ornstein, 1990; Fivush \& Schwarzmueller, 1995; Tucker et al., 1990) but only for 3- to 4-year-olds. Our findings suggest that an early initial interview (i.e., immediately following the event) may positively affect preschoolers' relevant recall a year later. It is difficult to comment on the consequences of multiple interviews for this youngest group 
who lacked an early initial interview since follow-up data are presently lacking. Future lines of research could investigate the impact of multiple interviews on preschool children when their initial questioning took place a year following their injury. For the older children, that is, children aged 5 to 9 years, it is known that there is no difference between those who had their initial interview one year following the incident and those who had their initial interview immediately following the injury. It would therefore be interesting to see how both of these age groups might differ when they each have more than one interview. That is, would the early initial interview group recall less, two years after the event, than those who had their initial interview one year after the injury, as proposed by Sutherland et al. (submitted for publication).

There has been evidence counter to what was discovered in the present study which suggests that repeated questioning, even when completely neutral, can have unanticipated harmful consequences (Warren \& Lane, 1995). Fivush and Hamond (1989) reported that children demonstrated more complete and accurate memories when they re-enacted an event twice versus only once, but they also advise that although the memories may be more complete and elaborate both accuracies and inaccuracies increase. This study's results disagree with this finding but, again, only in part. It was shown that multiple interviews or an early initial interview did not have a significant effect on the school-age children's accuracy, but the early initial interview did significantly influence the 3- and 4-year-olds' accuracy. This result occurred when only the data from the 3-and 4-year olds and 5-to 7-year-olds were analyzed across 1,2 , and 3 
interviews. However, when all three age groups receiving either 1 or 3 interviews were examined, the superior recollection of the older children (5- to 9-years-old) seemed to skew the data and subsequently raised the means and as a result, influenced only a borderline, non-significant result.

Notwithstanding, there is a difference between statistically significant and socially relevant. Although there is a significant effect of interview on the youngest children (3to 4 -year-olds) they were still $78 \%$ accurate, a very impressive accuracy level given that they had no initial interview to possibly systematize their memory. This result becomes forensically relevant when considering the ubiquity of delayed questioning within the criminal justice system and provides new evidence against the traditional view of questionable and non-credible recall of participants not interviewed soon after an incident.

It has been accepted that accuracy is best achieved in free recall (for review see Ceci \& Bruck, 1993). The present results are consistent with those findings. Children of all ages were amazingly accurate about those details they did recall under free recall conditions. However, there was also an interesting and somewhat contradictory finding involving the free recall of children whose first and only interview happened after a significant delay (i.e. one year). Several studies by Pipe and her colleagues have found that information generated for the first time in later interviews is generally inaccurate (Pipe, Gee, Wilson \& Egerton, 1999; Salmon \& Pipe, 2000; Salmon \& Pipe, 1997). Similarly, Peterson, Moores and White (2001) showed that new information introduced 1 
or 2 years post-injury was just as likely to be wrong as right. The results in the present study, however, show that for free recall those children who only had one interview and thus, would be recalling the information for the first time, had exceptional accuracy regardless of age $(90+\%)$. When analyzing total recall the results were just as impressive, regardless of age $(85+\%)$. In the Salmon and Pipe and Peterson et al. studies, children had the opportunity to recall at earlier times and what was inaccurate was only information that was not provided earlier, but added later. Thus, taking everything they recalled at 1 or 2 years into consideration, accuracy rates were also quite high in the Peterson et al. (2001) study. Presumably, if the children in the present study had been interviewed earlier they would have provided almost all of this information earlier. Thus, the low accuracy for the Salmon and Pipe and Peterson et al. studies occur when children have multiple opportunities for recall and some detail that is not recalled during those earlier interviews pops up later.

While legal professionals seem to believe that young children's memories are particularly sensitive to the passage of time, developmental psychology can now offer relevant data to challenge this presumption. The results from this study suggest that an early initial interview may play a significant role only for younger preschool children. Therefore, the practice of undermining a school age child's credibility because they did not receive early initial questioning about an event does not receive support from the present findings. Preschoolers' memory and subsequent recall however appear to be governed by different dynamics and are more precarious. From this study, it can be 
suggested that memory may have a social aspect and may be influenced by adult social interaction. Simply put, preschool children can essentially learn to structure and organize thoughts, ideas, concepts, and memories with formal, structured questioning, an ability that will naturally improve overtime, to some degree, by age 5. With early initial interviewing the adult can "scaffold" and systematically guide the organization of details and support the structure of memories, thus facilitating subsequent recall.

Through these findings, the author of the present study acknowledges and supports the fact that very young children can remember and recall traumatic events for a long time. Generally speaking the present research supports the consistent findings of Peterson's studies; that preschoolers can remember staggering amounts of detail with impressive accuracy over long delays. More specifically, however, it also outlines a new dynamic of this competency: not all young children have the same capacity for recall. That is, in the absence of an early initial interview, 3- and 4-year-olds' recall of an incident that occurred a year prior is still relatively complete and very accurate, which is impressive for their young age. However, their memory capabilities can be enhanced by an early well-organized, highly structured interview. From a forensic perspective, these results present data in support of the completeness of the memory and accurate recall of traumatic events over long delays by preschool and school age children. Our study also notes that even though preschoolers are remarkably accurate and complete in their recall over lengthy delays this ability can be augmented through formal, highly structured early interviewing. This finding is particularly relevant in assessing credibility of children's 
testimony since it outlines more precisely the possible dynamic and developmental characteristics of memory and subsequent ways to improve it. 
Influence of an Early Interview 48

\section{References}

Baker-Ward, L., Burgwyn, E., Ornstein, F.A., Gordon, B. (1995). Children's report of a minor medical emergency procedure. In G. Goodman \& L. Baker-Ward (Chairs), Children's memory for emotional and traumatic events. Symposium conducted at the Society for Research in Child Development, Indianapolis, $\mathbb{N}$.

Baker-Ward, L., Gordon, B.N., Ornstein, F.A., Larus, D., \& Clubb, P.A. (1993). Young children's retention of a pediatric examination. Child Development, 64, 15191533.

Baker-Ward, L, Hess, T.M. \& Flannagan, D.A. (1990). The effects of involvement on children's memory for events. Cognitive Development, 5, 55-69.

Boland, A.M., Haden, C.A. \& Ornstein, P. (submitted for publication). Boosting children's memory by training mothers in the use of an elaborative conversational style as an event unfolds.

Brainerd, C. J., \& Ornstein, P.A. (1990). Children's memory for witnessed events: The developmental backdrop. In J. Doris (Ed.), The suggestibility of children's recollections (p. 10-20). Washington, DC: American Psychological Association.

Brainerd, C. J., Reyna, V.F., Howe, M.L., \& Kingma, J. (1990). The development of forgetting and reminiscence. Monographs of the Society for Research in Child Development, 55 (3-4, Serial No. 222). 
Bruck, M., Ceci, S.J., \& Francouer, E. \& Barr, R. (1995). I hardly cried when I got my shot! Influencing children's memories about a visit to their pediatrician. Child Development, 66, 193-208.

Burgwyn-Bailes, E., Baker-Ward, L., Gordon, B., \& Ornstein, P. (2001). Children's memory for emergency treatment after one year: The impact of individual difference variables on recall and suggestibility. Applied Cognitive Psychology, $15,25-48$.

Ceci, S.J. \& Bruck, M. (1993). The suggestibility of the child witness: A historical review and synthesis. Psychological Bulletin, 113, 403-439.

Ceci, S.J. \& Bruck, M. (1995). Jeopardy in the courtroom: A scientific analysis of children's testimony. American Psychological Association: Washington, DC.

Christianson, S.A. (1992). Emotional Stress and eyewitness memory: A critical review. Psychological Bulletin, 112, 284-309.

Fivush, R., \& Hamond, N.R. (1989). Time and again: Effects of repetition and retention interval on 2 year olds' event recall. Journal of Experimental Child Psychology, $47,259-273$

Fivush, R., \& Hamond, N.R. (1990). Autobiographical memory across the preschool years. In R. Fivush \& J.S. Hudson (Eds.), Knowing and remembering in young children (pp. 223-248). Cambridge University Press: New York.

Fivush, R., Hamond, N.R., Harsch, N., Singer, N., \& Wolf, A. (1991). Content and consistency in early autobiographical recall. Discourse Processes, 14, 373-388. 
Fivush, R., Peterson, C. \& Schwarzmueller, A. (2002). Questions and answers: The credibility of child witnesses in the context of specific questioning techniques. In M.L. Eisen, G.S. Goodman, \& J.A. Quas (Eds.), Memory and suggestibility in the forensic interview (pp. 331-354). Mahwah, NJ: Erlbaum.

Fivush, R. \& Schwarzmueller, A. (1995). Say it once again: Effects of repeated questions on children's event recall. Journal of Traumatic Stress, 8, 555-580.

Fivush, R., \& Shukat, J.R. (1994). Content, consistency, and coherence of early autobiographical recall. In M.S. Zaragoza, J.R. Graham, G.C.N. Hall, R. Hirschman, \& Y.S. Ben-Porath (Eds.) Memory and testimony in the child witness (pp.5-23). Thousand Oaks, CA: Sage.

Flin, R. (1993). Hearing and testing children's evidence. In G.S. Goodman, \& B.L. Bottoms (Eds.), Child victims, child witnesses: Understanding and improving testimony (pp. 279-299). Guildford Press: New York.

Flin, R., Boon, J., Knox, A., \& Bull, R. (1992). The effect of a five-month delay on children's and adults' eyewitness memory. British Journal of Psychology, 83, 323-336.

Gold, E., \& Neisser, U. (1980). Recollections of kindergarten. Quarterly Newsletter of the Laboratory of Comparative Human Cognition, 2, 77-80.

Goodman, G.S., Hirschman, J.E., Hepps, D. \& Rudy, L. (1991). Children's memory for stressful events. Merrill-Palmer Quarterly, 37, 109-158. 
Influence of an Early Interview 51

Goodman, G.S., Quas, J.A., Batterman-Faunce, J.M., Riddlesberger, M.M., \& Kuhn, J. (1994). Predictors of accurate and inaccurate memories of traumatic events experienced in childhood. Consciousness and Cognition, 3, 269-294.

Goodman, G.S., Quas, J.A., Batterman-Faunce, J.M., Riddlesberger, M.M., \& Kuhn, J. (1997). Children's reaction to and memory for a stressful event: Influences of age, anatomical dolls, knowledge, and parental attachment. Applied Developmental Science, 1, 54-75.

Goodman, G.S., Taub, E.P., Jones, D.H.P., England, P., Port, L.K., Rudy, L., \& Prado, L. (1992). Testifying in criminal court: Emotional effects on child sexual abuse victims. Monographs of the Society for Research in Child Development, 57, (5, Serial No. 229).

Hayne, H. (1990). The effect of multiple reminders on long-term retention in human infants, Development Psychobiology, 23, 453-477.

Hoving, K.L., \& Choi, K. (1972). Some necessary conditions for producing reinstatement effects in children. Developmental Psychology, 7, 214-217.

Howe, M.L. (1991). Misleading children's story recall: Forgetting and reminiscence of the facts. Developmental Psychology, 27, 746-762.

Howe, M.L. (1997). Children's memory of traumatic experiences. Learning and Individual Differences, 9, 153-174.

Howe, M.L., Courage, M.L., Bryant-Brown, L. (1993). Reinstating preschoolers" memories. Developmental Psychology, 29, 854-869. 
Influence of an Early Interview 52

Hudson, J.A. (1990). Constructive processing in children's event memory. Developmental Psychology, 26, 80-187.

Hudson, J.A., \& Fivush, R. (1991). As time goes by: Sixth graders remember a kindergarten experience. Applied Cognitive Psychology, 5, 347-360.

Hudson, J.A., \& Sheffield, G. (1998). Déjà vu all over again: Effect of reenactment on toddlers' event memory. Child Development, 69, 51-67.

Jones, C., \& Pipe, M.E. (2002), How quickly do children forget events? A systematic study of children's event reports as a function of delay. Applied Cognitive Psychology, 16, 755-768.

Leichtman, M.D., Pillemer, D.B., Wand, Q., Koreishi, A. \& Han, J.J. (2000). When baby maisy came to school: Mother's interview styles and preschoolers' event memories. Cognitive Development, 15, 99-114.

Leippe, M.R., Mannion, A.P., \& Romancyzk, A. (1991). Eyewitness memory for a touching experience: Accuracy differences between child and adult witnesses. Journal of Applied Psychology, 76, 367-379.

McCabe, A. \& Peterson, C. (1991). Getting the story: A longitudinal study of parental styles in eliciting oral personal narratives and developing narrative skill. In A. McCabe \& C. Peterson (Eds.), Developing narrative structure (pp.217-253). Hillsdale, NJ: Erlbaum.

McGough, L.S. (1994). Child witnesses: Fragile voices in the American legal system. New Haven, CT: Yale University Press. 
Influence of an Early Interview 53

Merritt, K.A., Ornstein, P.A., \& Spicker, B. (1994). Children's memory for a salient medical procedure: Implications for testimony. Pediatrics, 94, 17-23.

Middleton, D., \& Edwards, D. (1990). Conversational remembering: A social psychological approach. In D. Middleton \& D. Edwards (Eds.), Collective remembering (23-45). London: Sage Publishing.

Ornstein, P.A., Baker-Ward, L., Gordon, B.N., Merritt, K.A. (1997). Children's memory for medical experiences: Implications for testimony. Applied Cognitive Psychology, 11, 87-104.

Peterson, C. (1996). The preschool child witness. Canadian Journal of Behavioural Science, 28, 36-42.

Peterson, C. (1999). Children's memory for medical emergencies: Two years later. Developmental Psychology, 35, 1493-1506.

Peterson, C. (2002). Children's long-term memory for autobiographical events. Developmental Review, 22, 370-402.

Peterson, C., \& Bell, M. (1996). Children's memory for traumatic injury. Child Development, 67, 3045-3070.

Peterson, C., \& Biggs, (1997). Interviewing children about trauma: Problems with "specific" questions. Journal of Traumatic Stress, 10, 279-290.

Peterson, C., Dowden, C., \& Tobin, J. (1999). Interviewing preschoolers: Comparison of yes/no and wh- questions. Law and Human Behaviour, 23, 539-555. 
Peterson, C., \& Grant, M. (2001). Forced choice: Are forensic interviewers asking the right questions? Canadian Journal of Behavioural Science, 33, 118-127.

Peterson, C., Jesso, B., \& McCabe, A. (1999). Encouraging narratives in preschoolers: An intervention study. Journal of Child Language, 26, 49-67.

Peterson, C., \& McCabe, A. (1983). Developmental Psycholinguistics: Three ways of looking at a child's narrative. Pleneum Press: New York.

Peterson, C., \& McCabe, A. (1992). Parental styles of narrative elicitation: Effect on children's narrative structure and content. First Language, 12, 299-321.

Peterson, C., Moores, L., \& White, G. (2001). Recounting the same event again and again: Children's consistency across multiple interviews. Applied Cognitive Psychology, 15, 353-371.

Peterson, C., Sales, J., \& Fivush, R. (unpublished). Factors affecting children's recall of injury.

Peterson, C., \& Whalen, N. (2001). Five years later: Children's memory for medical emergencies. Applied Cognitive Psychology, 15, 7-24.

Pillemer, D.B., Picariello, M.L., \& Pruett, J.C. (1994). Very long term memories of a salient preschool event. Journal of Applied Cognitive Psychology, 8, 539-556.

Pipe, M.E., Gee, S., Wilson, J.C., \& Egerton, J.M. (1999). Children's recall 1 or 2 years after an event. Developmental Psychology, 35, 781-789. 
Poole, D.A. \& White, L.T. (1993). Two years later: Effects of question repetition and retention interval on the eyewitness testimony of children and adults. Developmental Psychology, 29, 844-853.

Poole, D.A. \& White, L.T. (1995). Tell me again and again: Stability and change in the repeated testimonies of children and adults. In M.S. Zaragoza, J.R. Graham, G.C.N. Hall, R. Hirschman, \& Y.S. Ben-Porath (Eds.), Memory and testimony in the child witness (pp. 24-43). Thousand Oaks, CA: Sage.

Quas, J.A., Goodman, G.S., Bidrose, S., Pipe, M.E., Crew, S., \& Ablin, D.S. (1999). Emotion and memory: Children's long-term remembering, forgetting and suggestibility. Journal of Experimental Child Psychology, 72, 235-270.

Rapaport, D. (1942). Emotions and memory. Menninger Clinic Monograph Series No. 2. New York: Wiley.

Ross, D.F., Miller, B.S., \& Moran, P.B. (1987). The child in the eyes of the jury: Assessing mock jurors' perceptions of the child witness. In S. Ceci, M.P. Toglia, \& D.F. Ross (Eds.), Children's eyewitness memory (pp. 142-154). New York: Springer-Verlag.

Rovee-Collier, C. (1995). Time windows in cognitive development. Developmental Psychology, 31, 147-176.

Rovee-Collier, C., Greco-Vigorito, C. \& Hayne, H. (1993). The time-windowhypothesis: Implications for categorization and memory modification. Infant Behaviour and Development, 16, 149-176. 
Rovee-Collier, C. \& Shyi, G.C-W. (1992). A functional and cognitive analysis of infant long-term retention. In M.L. Howe, C.J. Brainerd, \& V.F. Reyna (Eds.), Development of long-term retention (pp.3-35). Springer-Verlag: New York.

Rudy, L., \& Goodman, G.S. (1991). Effects of participation on children's reports: Implications for children's testimony. Developmental Psychology, 27, 527-538.

Salmon, K, \& Pipe, M.E. (1997). Providing props to facilitate young children's reports: Implications for children's testimony. Developmental Psychology, 27, 527-538.

Salmon, K, \& Pipe, M.E. (2000). Recalling an event one year later: The impact of props, drawing and prior interview. Applied Cognitive Psychology, 14, 99-120.

Saywitz, K.J., Goodman, G.S., Nicholas, E., \& Moan, S.F. (1991). Children's memories of a physical examination involving genital touch: Implications for reports of sexual abuse. Journal of Consulting and Clinical Psychology, 59, 682-691.

Sutherland, R., Webster, N., Jones, C., LaRooy, D. \& Pipe, M.E. (submitted for publication). Do early interviews affect children's long-term event recall?

Tucker, A., Mertin, P., \& Luszcz, M. (1990). The effect of repeated interviews on young children's eyewitness memory. Australian and New Zealand Journal of Criminology, 23, 117-124.

Vandermaas, M.O., Hess, T.M., \& Baker-Ward, L. (1993). Does anxiety affect children's reports of memory for a stressful event? Journal of Applied Psychology, 7, 109-128.

Vygotsky, L. (1934/1986). Thought and Language. Cambridge, MA: MT Press. 
Warren, A.R., \& Lane, P. (1995). Effects of timing and type of questioning on eyewitness accuracy and suggestibility. In M.S. Zaragoza, J.R. Graham, G.C. Hall, R. Hirschman, \& Y.S. Ben-Porath (Eds.), Memory and testimony in the child witness (45-60). London: Sage Publishing.

Warren, A.R., \& Swartwood, J.N. (1992). Developmental issues in flashbulb memory research: Children recall the Challenger event. In E. Winograd \& R. Neisser (Eds.), Affect and accuracy in recall: Studies of flashbulb memories (pp. 95-120). New York: Cambridge. 
Influence of an Early Interview 58

Table 1

Specific Age Group Sample Size, Mean Age and Age Range for each Interview Group

\begin{tabular}{|c|c|c|c|c|c|c|c|c|c|}
\hline \multirow{3}{*}{ Interview(s) } & \multicolumn{9}{|c|}{ Age Groups } \\
\hline & \multicolumn{3}{|c|}{$3-4$} & \multicolumn{3}{|c|}{$5-7$} & \multicolumn{3}{|c|}{ 8-9 } \\
\hline & $\mathbf{n}$ & $\begin{array}{l}\text { M age } \\
\text { (years, } \\
\text { months) }\end{array}$ & $\begin{array}{c}\text { Age } \\
\text { Range } \\
\text { (years, } \\
\text { months) }\end{array}$ & n & $\begin{array}{l}\text { M age } \\
\text { (years, } \\
\text { months) }\end{array}$ & $\begin{array}{c}\text { Age } \\
\text { Range } \\
\text { (years, } \\
\text { months) }\end{array}$ & $\mathbf{n}$ & $\begin{array}{c}\text { M age } \\
\text { (years, } \\
\text { months) }\end{array}$ & $\begin{array}{c}\text { Age } \\
\text { Range } \\
\text { (years, } \\
\text { months) }\end{array}$ \\
\hline $\begin{array}{l}12 \text { months } \\
\text { (present study) }\end{array}$ & 18 & $3,8.5$ & $\begin{array}{c}2,11.5- \\
4,11.5\end{array}$ & 17 & $6,4.5$ & $\begin{array}{c}5,2- \\
7,11.5\end{array}$ & 18 & 9,1 & $\begin{array}{c}8,2- \\
9,9.5\end{array}$ \\
\hline $\begin{array}{l}0 \text { and } 12 \\
\text { months } \\
\text { (comparison group) }\end{array}$ & 18 & $3,9.5$ & $\begin{array}{l}2,6- \\
4,11\end{array}$ & 17 & 5,8 & $\begin{array}{l}5,2- \\
6,10\end{array}$ & N/A & N/A & N/A \\
\hline $\begin{array}{c}0,6 \text { and } 12 \\
\text { months } \\
\text { (comparison group) }\end{array}$ & 18 & 3,9 & $\begin{array}{l}3,2- \\
4,9\end{array}$ & 17 & 5,9 & $\begin{array}{l}5,4- \\
6,11\end{array}$ & 18 & $8,8.5$ & $\begin{array}{c}8- \\
9,11\end{array}$ \\
\hline
\end{tabular}


Table 2

Mean Percentages of Completeness of Memory Scores by Age and Number of Interviews for Total Recall

\begin{tabular}{|c|c|c|c|c|c|}
\hline \multirow{2}{*}{ Interview(s) } & \multirow{2}{*}{$\begin{array}{c}\text { Age in } \\
\text { Years }\end{array}$} & \multicolumn{4}{|c|}{ Event Type } \\
\cline { 3 - 6 } & & \multicolumn{3}{|c|}{ Injury } & \multicolumn{2}{c|}{ Hospital } \\
\cline { 3 - 6 } & & $\mathbf{M}$ & SD & M & SD \\
\hline \multirow{3}{*}{12 months } & $3-4$ & 60.34 & 14.08 & 36.33 & 15.21 \\
\cline { 2 - 6 } & $5-7$ & 75.73 & 14.97 & 55.78 & 14.71 \\
\cline { 2 - 6 } & $8-9$ & 82.51 & 10.28 & 62.44 & 15.67 \\
\hline \multirow{3}{*}{0 and 12 months } & & & & & \\
\cline { 2 - 6 } & $3-4$ & 68.45 & 17.72 & 46.20 & 19.20 \\
\cline { 2 - 6 } & $8-7$ & 68.41 & 20.34 & 51.38 & 20.61 \\
\hline & & $\mathrm{N} / \mathrm{A}$ & $\mathrm{N} / \mathrm{A}$ & $\mathrm{N} / \mathrm{A}$ & $\mathrm{N} / \mathrm{A}$ \\
\hline \multirow{3}{*}{$\mathbf{0} 6$ and 12 months } & $3-4$ & 68.41 & 13.15 & 49.99 & 14.43 \\
\cline { 2 - 6 } & $5-7$ & 78.10 & 10.51 & 63.26 & 11.49 \\
\cline { 2 - 6 } & $8-9$ & 75.67 & 12.03 & 59.82 & 14.44 \\
\hline
\end{tabular}


Table 3

Mean Percentages of Accuracy Scores by Age and Number of Interviews for Total Recall

\begin{tabular}{|c|c|c|c|c|c|}
\hline \multirow{2}{*}{ Interview(s) } & \multirow{2}{*}{$\begin{array}{l}\text { Age in } \\
\text { Years }\end{array}$} & \multicolumn{4}{|c|}{ Event Type } \\
\cline { 3 - 6 } & & \multicolumn{2}{|c|}{ Injury } & \multicolumn{2}{|c|}{ Hospital } \\
\cline { 2 - 6 } & & $\mathbf{M}$ & SD & M & SD \\
\hline \multirow{3}{*}{12 months } & $3-4$ & 81.71 & 11.82 & 69.80 & 15.33 \\
\cline { 2 - 6 } & $5-7$ & 85.96 & 17.46 & 81.02 & 12.80 \\
\cline { 2 - 6 } & $8-9$ & 93.70 & 5.79 & 87.31 & 13.20 \\
\hline \multirow{3}{*}{0 and 12 months } & & & & & \\
\cline { 2 - 6 } & $3-4$ & 78.77 & 17.86 & 73.99 & 25.78 \\
\cline { 2 - 6 } & $5-7$ & 83.65 & 9.62 & 74.13 & 19.56 \\
\hline & $8-9$ & N/A & N/A & N/A & N/A \\
\hline \multirow{3}{*}{0,6 and 12 months } & $3-4$ & & & & \\
\cline { 2 - 6 } & $5-7$ & 85.95 & 11.38 & 77.29 & 18.01 \\
\cline { 2 - 6 } & $8-9$ & 90.34 & 8.38 & 88.59 & 11.59 \\
\hline
\end{tabular}


Table 4

The Number of Children Not Providing Information in Free Recall.

\begin{tabular}{|c|c|c|c|}
\hline \multirow{2}{*}{ Interview(s) } & \multirow{2}{*}{ Age in Years } & \multicolumn{2}{|c|}{ Free Recall } \\
\cline { 2 - 4 } & & Injury & Hospital \\
\hline \multirow{3}{*}{12 months } & $3-4$ & 3 & 7 \\
\cline { 2 - 4 } & $5-7$ & 0 & 1 \\
\cline { 2 - 4 } & $8-9$ & 0 & 2 \\
\hline \multirow{3}{*}{0 and 12 months } & & & \\
\cline { 2 - 4 } & $3-4$ & 1 & 8 \\
\cline { 2 - 4 } & $5-7$ & 3 & 3 \\
\hline & $8-9$ & N/A & N/A \\
\hline \multirow{2}{*}{0,6 and 12 months } & $3-4$ & & 0 \\
\cline { 2 - 4 } & $5-7$ & 2 & 0 \\
\cline { 2 - 4 } & $8-9$ & 0 & 0 \\
\hline
\end{tabular}


Table 5

Mean Percentages of Completeness of Memory Scores by Age and Number of Interviews for Free Recall

\begin{tabular}{|c|c|c|c|c|c|}
\hline \multirow{2}{*}{ Interview(s) } & \multirow{2}{*}{$\begin{array}{c}\text { Age in } \\
\text { Years }\end{array}$} & \multicolumn{4}{|c|}{ Event Type } \\
\cline { 3 - 6 } & & \multicolumn{3}{|c|}{ Injury } & \multicolumn{2}{|c|}{ Hospital } \\
\cline { 3 - 6 } & $3-4$ & 20.72 & 10.40 & 10.32 & 5.69 \\
\hline \multirow{3}{*}{12 months } & $5-7$ & 28.60 & 12.48 & 16.80 & 10.05 \\
\cline { 2 - 6 } & $8-9$ & 46.06 & 19.32 & 25.16 & 22.31 \\
\cline { 2 - 6 } & & & & & \\
\hline \multirow{3}{*}{ Ond 12 months } & $3-4$ & 25.33 & 13.27 & 10.24 & 4.75 \\
\cline { 2 - 6 } & $5-7$ & 31.08 & 23.00 & 13.73 & 6.88 \\
\cline { 2 - 6 } & $8-9$ & $\mathrm{~N} / \mathrm{A}$ & $\mathrm{N} / \mathrm{A}$ & $\mathrm{N} / \mathrm{A}$ & $\mathrm{N} / \mathrm{A}$ \\
\hline & & & & & \\
\hline \multirow{3}{*}{$\mathbf{0 , 6}$ and 12 months } & $3-4$ & 25.84 & 17.13 & 16.41 & 8.88 \\
\cline { 2 - 6 } & $5-7$ & 39.04 & 17.00 & 22.21 & 12.68 \\
\cline { 2 - 6 } & $8-9$ & 46.00 & 17.30 & 31.47 & 12.18 \\
\hline
\end{tabular}


Table 6

Mean Percentages of Accuracy Scores by Age and Number of Interviews for Free Recall

\begin{tabular}{|c|c|c|c|c|c|}
\hline \multirow{3}{*}{ Interview(s) } & \multirow{3}{*}{$\begin{array}{l}\text { Age in } \\
\text { Years }\end{array}$} & \multicolumn{4}{|c|}{ Event Type } \\
\hline & & \multicolumn{2}{|c|}{ Injury } & \multicolumn{2}{|c|}{ Hospital } \\
\hline & & $M$ & SD & $\bar{M}$ & SD \\
\hline \multirow{3}{*}{12 months } & $3-4$ & 98.57 & 5.35 & 86.36 & 32.33 \\
\hline & $5-7$ & 95.88 & 12.78 & 96.88 & 12.50 \\
\hline & $8-9$ & 96.85 & 5.57 & 96.88 & 8.54 \\
\hline & & & & & \\
\hline \multirow{3}{*}{0 and 12 months } & $3-4$ & 97.06 & 8.81 & 96.67 & 10.54 \\
\hline & 5-7 & 89.05 & 26.91 & 92.86 & 18.16 \\
\hline & $8-9$ & N/A & $\mathrm{N} / \mathrm{A}$ & N/A & $\mathrm{N} / \mathrm{A}$ \\
\hline & & & & & \\
\hline \multirow{3}{*}{0,6 and 12 months } & 3-4 & 98.74 & 3.80 & 97.04 & 8.92 \\
\hline & $5-7$ & 99.61 & 1.52 & 93.14 & 24.34 \\
\hline & $8-9$ & 95.89 & 7.61 & 99.31 & 2.95 \\
\hline
\end{tabular}


Influence of an Early Interview 64

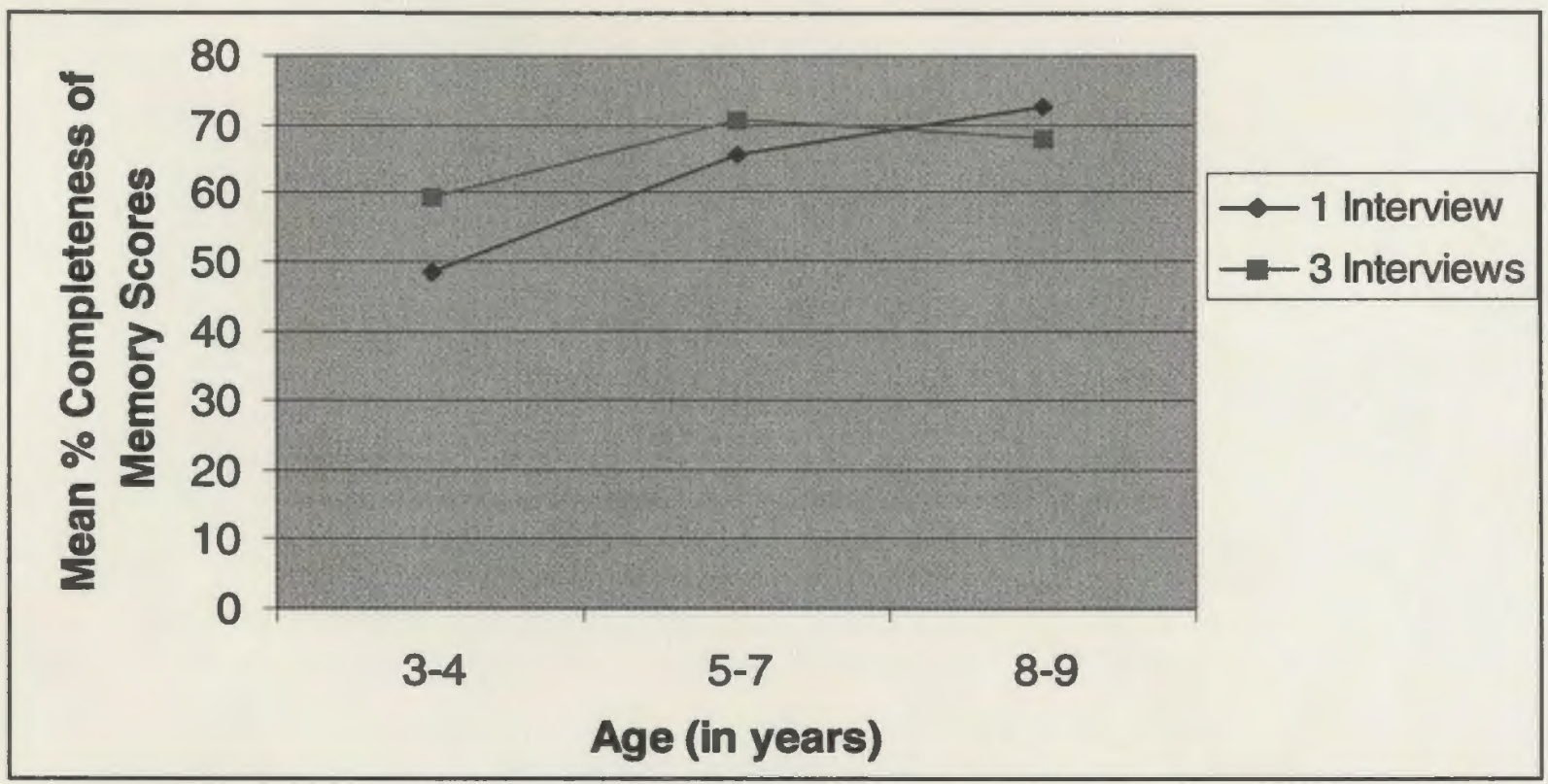


Influence of an Early Interview 65

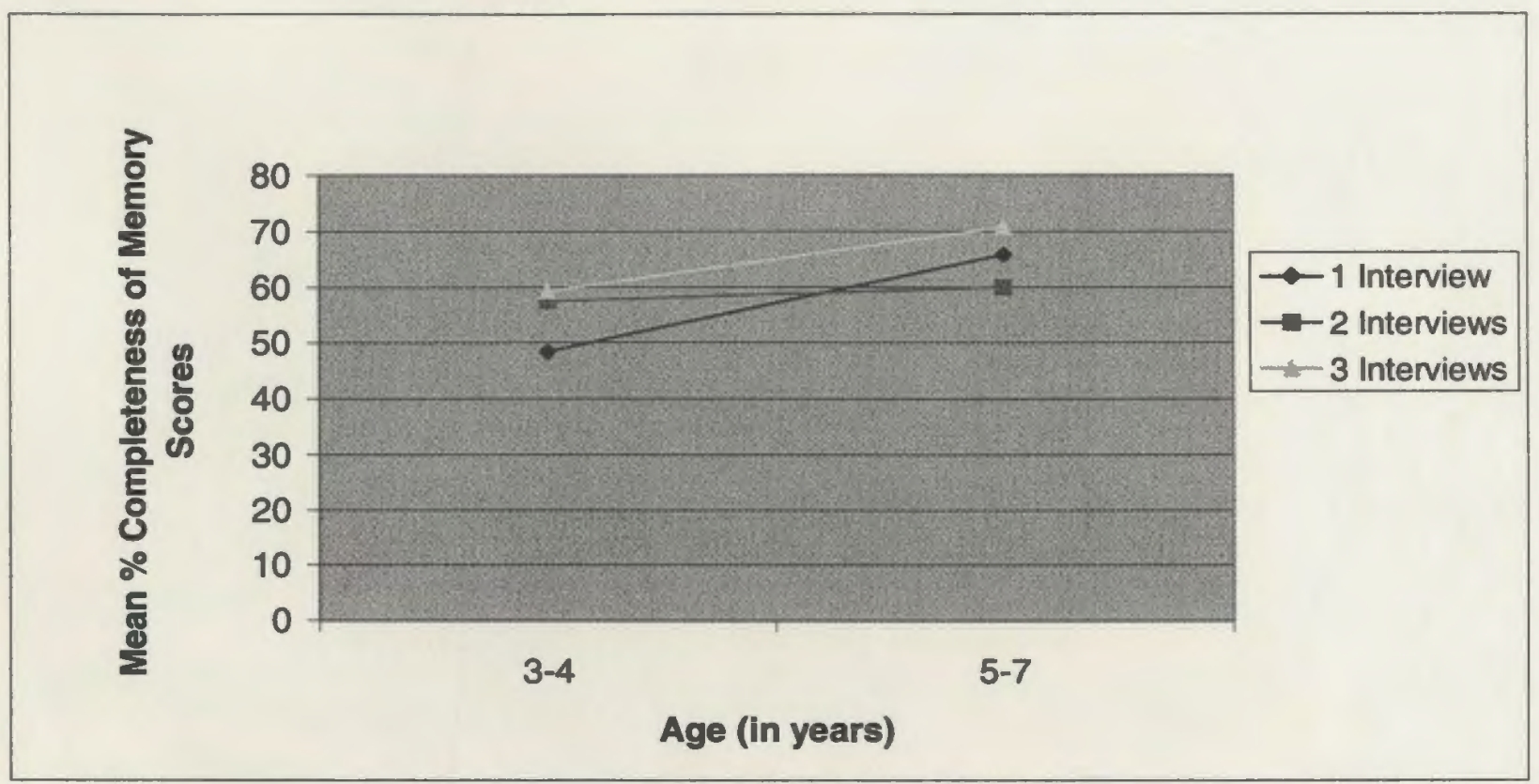


Appendix A

Prototype of Injury and Hospital Treatment Classification with Corresponding Sample Questions

INJURY

Item

Time of Day

Place

Who was with you

Who else was around

Actions prior to injury

What happened

How it occurred

Who did it

What objects were involved

Cry

Blood

Who first responded

Where you went before hospital

Actions to treat injury prior to hospital visit

Objects of this treatment

Anyone else look/help

\section{Sample Responses}

"Right after lunch"

"In my backyard"

"Mom and my brother Joe"

"My friend Anna was playing there too"

"I was running"

"I got a cut on my leg"

"I was tripped"

"By my brother"

"I hit a piece of porch that was sticking up"

"I cried a lot"

"It was bleeding all down my leg"

"Mommy heard my cry and picked me up"

"She took me into the bathroom"

"She wiped my knee"

"Put a cloth on my knee to soak the blood"

"My brother was watching" 
Went to hospital

Who took you to hospital

Who else went along

Time of hospital trip

\section{HOSPITAL}

Item

Registration

Vitals measured

Waiting period

Actions while waiting

Initial Exam

Hospital Personnel

X-rays

Cast

Needles

Stitches

Bandage

Sheet

Procedural details

Other treatment details

Cry
"Then I went to the hospital"

"Mom drove me there"

"My brother had to come too"

"We got the hospital a half an hour later"

\section{Example}

"A nurse checked me in"

"I had to get my temperature taken"

"We had to wait a long while"

"I coloured some pictures"

"Finally someone looked at my cut"

"It was a girl doctor"

"They took pictures of my knee"

(not relevant)

"I got 4 needles to put my knee asleep"

"Then they gave me 14 stitches"

"I got a big bandage all down my leg"

"They wrapped me in a big sheet"

"The doctor cleaned my cut first"

"They put polysporin on the stitches"

"I screeched when they gave me needles" 
Popsicle

Family in treatment room
"The nurse gave me a yellow popsicle"

"My mom and brother were there with me" 


